\title{
Asynchronous Terrestrial and Marine Signals of Climate Change During Heinrich Events
}

\author{
Tim C. Jennerjahn, ${ }^{1 *}$ Venugopalan Ittekkot, ${ }^{1}$ Helge W. Arz, ${ }^{2}$ \\ Hermann Behling, ${ }^{3}$ Jürgen Pätzold, ${ }^{3}$ Gerold Wefer ${ }^{3}$
}

Tropical regions have been reported to play a key role in climate dynamics. To date, however, there are uncertainties in the timing and the amplitude of the response of tropical ecosystems to millennial-scale climate change. We present evidence of an asynchrony between terrestrial and marine signals of climate change during Heinrich events preserved in marine sediment cores from the Brazilian continental margin. The inferred time lag of about 1000 to 2000 years is much larger than the ecological response to recent climate change and appears to be related to the nature of hydrological changes.

The recent increase in extreme climatic events, particularly in tropical regions, is thought by many to be a precursor of climate change. High-resolution investigations of past climate oscillations have found that changes between climate modes (warm versus cold and dry versus wet) can occur within decades (1), a period of time similar to that of recent climate change. Hence, understanding the controls of past high-frequency climate oscillations is a prerequisite for improving recent climate prediction. Occurrences of high-amplitude climate changes in the tropics during the past decade suggest that clues about the causes of climate instability during the Quaternary might be found in tropical regions (2). Despite a growing pool of highresolution paleoclimate records from low latitudes, detailed knowledge on the distribution and amplitude of climate changes in space and time is still sparse, and the processes responsible are hardly understood (3). Uncertainties exist particularly in reconciling timing and amplitude of responses of tropical terrestrial and marine ecosystems to climate changes (4-6). Generally, it is assumed that the response of vegetation patterns lags climatic changes. Estimates of the lag range between decades on an ecosystem scale to 2000 to 3000 years on a continent scale but are mostly derived from records spanning the deglacial and Holocene periods $[(7,8)$ and references therein]. However, estimates from the Pleistocene, with its millennial-scale climate oscillations, suffer from a lack of archives with variables independently denoting climate change and vegetation response. Un-

\footnotetext{
${ }^{1}$ Zentrum für Marine Tropenökologie, Fahrenheitstrasse 6, D-28359 Bremen, Germany. ${ }^{2}$ GeoForschungsZentrum Potsdam, Telegrafenberg, 14473 Potsdam, Germany. ${ }^{3}$ Deutsche Forschungsgemeinschaft (DFG) Forschungszentrum Ozeanränder (RCOM), Klagenfurter Strasse, 28359 Bremen, Germany.

*To whom correspondence should be addressed. E-mail: tim.jennerjahn@zmt-bremen.de
}

derstanding the processes determining the ecological response time to climate change is a prerequisite for meaningful use of terrestrial proxies in the interpretation of paleoclimate data. It also requires high-resolution climate archives from sites that are sensitive to changes in regional climate systems and capable of recording marine as well as terrestrial ecosystems' responses to climate change.

We found such a site on the continental margin off northeast Brazil (Fig. 1). Sediment cores covering late Quaternary sediments dating back to 85,000 years before the present (B.P.) were studied for information on oceanic and terrestrial responses to cli-

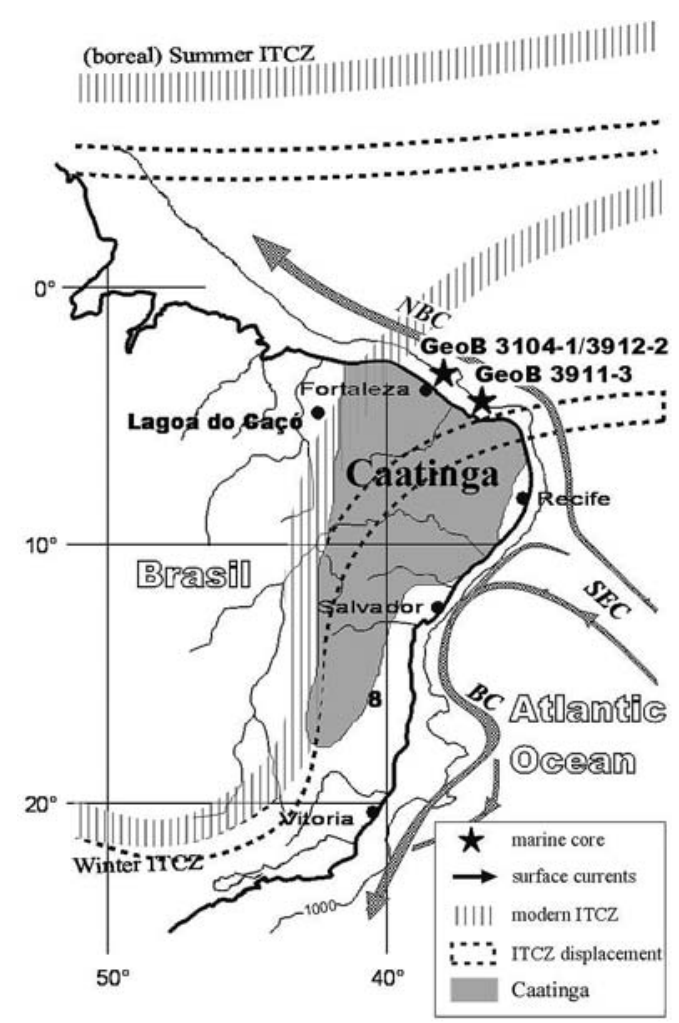

mate change by using a multiproxy approach. The area is situated between two moisture-carrying trade wind systems sensitive to climate changes caused by seasonal movements of the Intertropical Convergence Zone (ITCZ) (9) and exhibit high sedimentation rates. Thus, it is suitable for monitoring the consequences of high-frequency climate oscillations in the tropical Atlantic Ocean as well as on the South American continent.

Distribution patterns of newly obtained data on organic carbon $\left(\mathrm{C}_{\text {org }}\right)$ and carbonate $\left(\mathrm{CaCO}_{3}\right)$ contents and stable carbon and nitrogen isotopes $\left(\delta^{13} \mathrm{C}_{\text {org }}\right.$ and $\left.\delta^{15} \mathrm{~N}\right)$ in our cores are in agreement with previously measured geochemical parameters, pollen abundance and composition, and $\mathrm{Fe} / \mathrm{Ca}$ and $\mathrm{Ti} / \mathrm{Ca}$ ratios. They indicate millennial-scale sedimentation pulses coincident with the Younger Dryas (YD) and Heinrich events H1 to H8 known from the North Atlantic (9) (Figs. 2 and 3), although the time spans of the sedimentation pulses we observed do not always match exactly with those of the North Atlantic events. The most important finding of our study is a recurring internal sedimentation pattern during Heinrich events with opposing gradual changes in the parameters measured. The sedimentation rate increased from 10 to $15 \mathrm{~cm} \mathrm{kyear}{ }^{-1}$ to maxima to $30 \mathrm{~cm}$ kyear $^{-1}$ during Heinrich events (10). Rapid decreases of $\mathrm{CaCO}_{3}$ content from 30 to $40 \%$ in the beginning of a Heinrich event to $<10 \%$ were accompanied by rapid increases of $\mathrm{Fe} / \mathrm{Ca}$ and $\mathrm{Ti} / \mathrm{Ca}$ ratios, indicating a shift from car-
Fig. 1. Map of the investigated area with locations of cores GeoB 3104-1/ GeoB 3912-1 (3 $3^{\circ} 40.0^{\prime} \mathrm{S}, 37^{\circ} 43.0^{\prime} \mathrm{W}$, and 767-m water depth) and GeoB 3911-3 $\left(4^{\circ} 36.8^{\prime} \mathrm{S}, 36^{\circ} 38.2^{\prime} \mathrm{W}\right.$, and $828-\mathrm{m}$ water depth), and Lagoa do Caçó ( $2^{\circ} 58^{\prime} \mathrm{S}$ and $43^{\circ} 25^{\prime} \mathrm{W}$ ), as well as the actual positions of the ITCZ and its inferred southward displacement during the times of Heinrich events as suggested by our data. Also included are the major surface currents: the South Equatorial Current (SEC), the North Brazil Current (NBC), and the Brazil Current (BC). The major vegetation type of northeast Brazil is caatinga (primarily xerophytic thorn shrub), which is bordered by cerrado (savannah) to the west and Atlantic rainforest along the coastal stretch. 
bonate to lithogenic deposition (11). After this initial increase, $\mathrm{Fe} / \mathrm{Ca}$ and $\mathrm{Ti} / \mathrm{Ca}$ ratios then gradually decreased toward the end of a Heinrich event. In contrast, the $\mathrm{C}_{\text {org }}$ content in our cores gradually increases from about $0.5 \%$ to $2.7 \%$ during Heinrich events, with a maximum near their ends $\delta^{13} \mathrm{C}_{\text {org }}$ decreased from values between -20 per mil (\%o) and $-21 \%$, indicating its marine origin (12), to values between $-23 \%$ and $-24 \%$. The $3 \%$ o decrease of $\delta^{13} \mathrm{C}_{\text {org }}$ indicates a substantial contribution of terrestrial organic matter (OM) (Figs. 2 and 3). The latter may consist of plant, soil, and plankton, which has a $\delta^{13} \mathrm{C}_{\text {org }}$ that is almost similar to but distinctly different from that of marine OM (13). $\delta^{15} \mathrm{~N}$ gradually decreased from about $10 \%$ to $5.5 \%$ in GeoB 3912-1 and from about $13 \%$ to $4.5 \%$ in GeoB 3911-3 toward the end of an event.

Variations in $\delta^{15} \mathrm{~N}$ should reflect changes in $\mathrm{OM}$ source and quality, with high values denoting high degrees of $\mathrm{OM}$ degradation during times of normal sedimentation and the onset of Heinrich events (14). Increased contribution of terrestrial plant materials, which meet part of their nitrogen demand by atmospheric nitrogen fixation $\left(\delta^{15} \mathrm{~N}=\right.$ $0 \%$ ), and less degradation of the OM may have led to the lower $\delta^{15} \mathrm{~N}$ values observed during YD and Heinrich events. In conjunction with decreasing $\delta^{13} \mathrm{C}_{\text {org }}$, the subsequent shift of $\delta^{15} \mathrm{~N}$ toward values observed in modern riverine and mangrove sediments indicates an increasing contribution of less degraded OM, mainly of terrestrial origin.

The fluxes and composition of pollen and fern spores generally display a similar distribution. Pollen influx gradually increased from $<10$ grains $\mathrm{cm}^{-2}$ year ${ }^{-1}$ in the beginning of Heinrich events to a maximum of 60 grains $\mathrm{cm}^{-2}$ year $^{-1}$ in the second half of H1 (10). Fern spore fluxes indicate a successional vegetation pattern. Moss fern (Selaginella) fluxes increased rapidly during the first half and then decreased gradually toward the end of H1. In contrast, tree fern fluxes increase gradually from minimal flux in the beginning to a maximum in the end of H1. The lacustrine pollen record from Lagoa do Caçó displays a similar pattern. Taxa reflecting rapid reforestation in response to increased moisture were found at about 16 calendar kyear B.P. (15), not exactly at the

Fig. 2. Multiproxy sedimentation patterns of core GeoB 3104-1/GeoB 3912-1 from the past 85 kyear. Core GeoB 3912-1 extends the 48kyear B.P. record of core GeoB 3104-1 to 86 kyear B.P. (9). Accelerator mass spectrometry (AMS) ${ }^{14} \mathrm{C}$ ages (black arrows) (9) and stratigraphic correlation with the Spectral Mapping Project (SPECMAP) $\delta^{18} \mathrm{O}$ stack were used for age control. Time resolution of core $\mathrm{GeoB}$ $3104-1 / 3912-1$ is about 200 years. (A) Moss fern (dashed line) and tree fern (solid line) spore fluxes in core GeoB 3104. (B) Pollen influx in core GeoB 3104-1 (10). (C) $\delta^{15} \mathrm{~N}$ of core GeoB 3912-1, given in $\%$ versus atmospheric air. (D) $\delta^{13} C_{\text {org }}$ of core GeoB 3912-1, given in $\%$ versus pee dee belemnite (PDB). (E) $\mathrm{C}_{\text {org }}$ content of core GeoB 3912-1. (F) Fe/Ca ratio of core GeoB 3912-1 (9). Timing of YD based on (33); $\mathrm{H} 1$ to $\mathrm{H} 5,(35)$; and $\mathrm{H} 6$ to $\mathrm{H} 8,(36)$. Shaded areas representing sedimentation pulses coincident with the YD and $\mathrm{H} 1$ to $\mathrm{H} 8$ are defined according to drastic changes in the Fe/Ca ratio. same time we found maximum pollen and fern spore fluxes and terrigenous $\mathrm{OM}$ in our cores but also considerably lagging the onset of H1 (Figs. 2 and 3).

The internal sedimentation pattern during Heinrich events indicates an asynchrony between the response of marine and terrestrial ecosystems to rapid millennial-scale changes. On the basis of an observed increase of $\mathrm{Fe} / \mathrm{Ca}$ and $\mathrm{Ti} / \mathrm{Ca}$ ratios, the Heinrich events as a whole were previously thought to be periods of increased input of terrigenous materials resulting from increased precipitation and river discharge (9). Our newly obtained biogeochemical and stable isotope data, in combination with previous findings, allow us to better resolve the deposition history of these millenial-scale oscillations. In the beginning of such a Heinrich-type event, increased precipitation along the continental margin of northeast Brazil led to an initial outwash of exposed shelf sediments and increased river inputs of eroded topsoil, both poor in OM (16). This erosion period is indicated by high $\mathrm{Fe} / \mathrm{Ca}$ and $\mathrm{Ti} / \mathrm{Ca}$ ratios and low $\mathrm{OM}$ and pollen contents observed in our cores. Only pioneer vegetation like moss ferns, with a peak flux in the middle of H1, grew during this phase. Subsequently, the vegetation cover, including regionwide development of gallery and floodplain rainforests and montane forest, slowly expanded, stabilized the soil, and reduced erosion of OM-depleted mineral matter in the second half of H1. This expansion is indicated by the peak fluxes of tree fern spores and pollen in the second half of H1 (Fig. 2). In the second half of these wet periods, the enhanced production of fresh terrestrial $\mathrm{OM}$ and increased discharge of the rivers directly on the continental slope led to the observed high $\mathrm{OM}$, pollen, and fern spore contents and low $\delta^{13} \mathrm{C}_{\text {org }}$ and $\delta^{15} \mathrm{~N}$ in our cores.

We infer that the successional pattern from marine to terrigenous sedimentation within the pulses is a consequence of a time lag, on the order of 1000 to 2000 years, between the onset of rapid millennial-scale changes and the response of the continental bio- and geospheres. Our record preserved terrestrial as well as marine signals of climate change. It has an advantage over the traditional correlation of terrestrial with marine climate archives by avoiding chronology problems that become fundamental when correlating high-frequency records of climate change over great distances (17). The time lag we postulate cannot be just the transit time from the terrestrial source of the material to its marine sink for the following reasons. First, if the expansion of vegetation cover and increased fluvial input of eroded soil rich in the freshly produced plant OM were coeval with the rapid hydrological changes, 


\section{R E P O R T S}

we should have observed a peak of terrestrial $\mathrm{OM}$ in the beginning of the Heinrich events. Second, $\mathrm{Fe} / \mathrm{Ca}$ and $\mathrm{Ti} / \mathrm{Ca}$ ratios reflecting the input of lithogenics should have been high throughout the whole Heinrich event if there was no regulation by the increasing vegetation cover that gradually stabilized the soil and reduced erosion. Third, if the observed pattern were simply an artifact of material transport, the rise of pollen in the Lagoa do Caçó record should have preceded and not lagged that of our marine core.

The postulated time lag in our regionalscale example is much longer than the ecological response to recent climate change, which can be in the range of decades (18). It is also much longer than a time lag of a few decades postulated for the response of tropical vegetation to abrupt climate changes during the last deglaciation and derived from sedimentary records of climate and biomarker proxies in the Cariaco Basin (7). The reason for this apparent contradiction may lie in the difference of the prevailing climate and hydrology in the two regions. Like in the late Pleistocene, northeast Brazil currently is characterized by a semi-arid climate and caatinga vegetation (10). The dry period of about 8 months does not allow the development of rainforests that cannot survive a dry period longer than 4 months. It is conceivable that in the beginning of Heinrich events precipitation intensity rapidly increased during the rainy austral summer but not throughout the whole year. This first promoted erosion of the bare landscape. Subsequently, the seasonality of rainfall may have shifted toward a dry period shorter than 4 months, eventually allowing a regionwide expansion of wet forests. In the Cariaco Basin watershed, with its lowland and montane rainforest vegetation, annual precipitation is much higher and the contrast between dry and wet seasons less pronounced than in northeast Brazil. This would explain the almost immediate ecological response to climate change in the range of decades for the deglacial period in the Cariaco Basin watershed (7).

A detailed look at the differences in the amplitude of changes among Heinrich events provides further insight into the response of terrestrial and marine ecosystems to climate change. We found the maximum amplitude of changes during the longest lasting events, $\mathrm{H} 1$ and H6, in our cores. Pollen and fern
Fig. 3. Multiproxy sedimentation patterns of cores GeoB 3104-1/ GeoB 3912-1 (red lines) and GeoB 3911-3 (blue lines) from the past 21 kyears compared with other paleoclimate indicators. AMS ${ }^{14} \mathrm{C}$ ages (blue arrows) (9) were used for age control in core GeoB 3911-3. Time resolution of core GeoB 3911-3 is about 60 years. (A) Moss fern (dashed line) and tree fern (solid line) spore fluxes in core GeoB 3104. (B) Pollen influx in core GeoB 3104-1 (left axis) and percentage of arboreal pollen (black line, right axis) in the lacustrine record of Lagoa do Caçó (15), northeast Brazil. (C) $\delta^{15} \mathrm{~N}$ of core GeoB 3912-1, given in \%o versus atmospheric air. (D) $\delta^{13} C_{\text {org }}$ of core GeoB 3912-1, given in \% versus PDB. (E) $\mathrm{C}_{\text {org }}$ content of core GeoB 3912-1. (F) $\mathrm{Fe} / \mathrm{Ca}$ ratio of core GeoB 3912-1 (9).

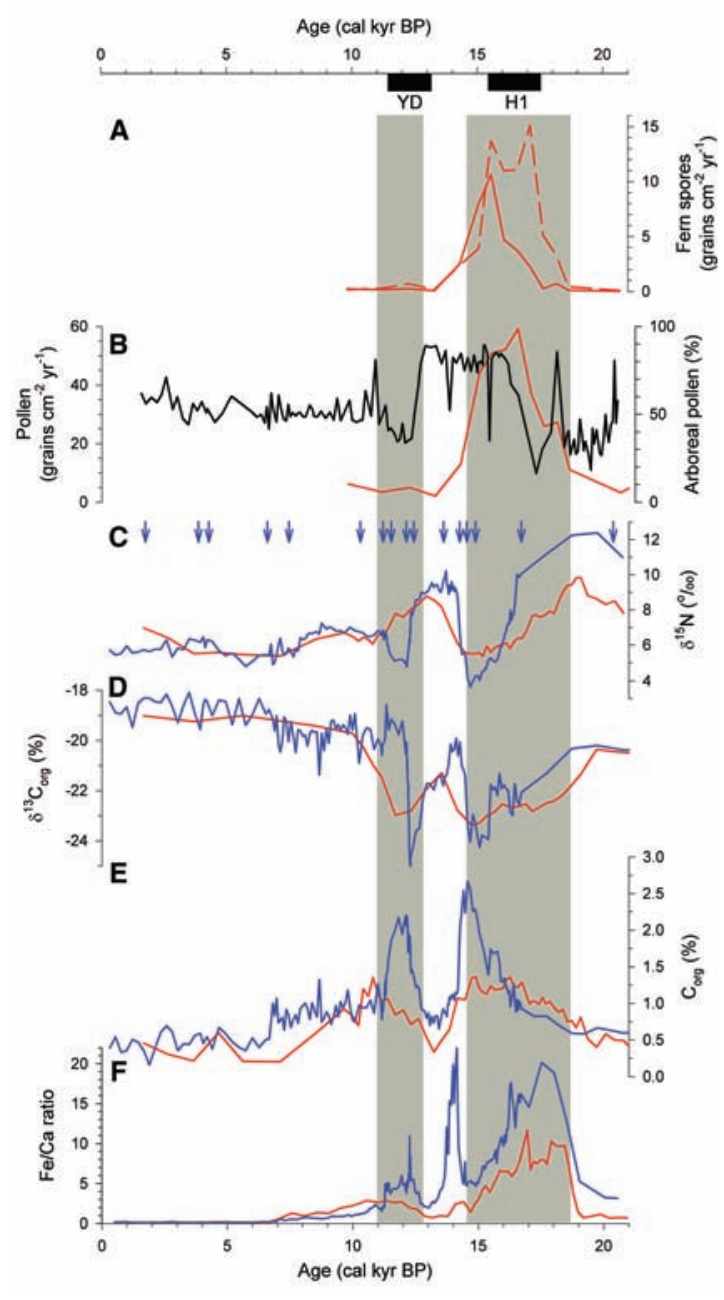

spore fluxes are much lower during the shorter events, $\mathrm{H} 2$ to $\mathrm{H} 5$, and in the case of H5 they are out of phase with the other records. Low pioneer vegetation like moss ferns developed during all Heinrich events. Wet forests including tree ferns, however, could expand only during $\mathrm{H} 1$, as indicated by high fluxes during $\mathrm{H} 1$ and otherwise low fluxes of tree fern spores (Fig. 2). Our findings indicate that the magnitude of events $\mathrm{H} 2$ to $\mathrm{H} 5$, despite an overall increase in annual precipitation, may have been too small for a change of the seasonal distribution and thus the regionwide expansion of wet forests in northeast Brazil. Assuming that the abrupt vegetation change following deglacial climate change observed in Cariaco Basin sediments (7), which is in accordance with present-day observations (18), reflects the true ecological response to climate change, we infer that the delayed response of the continental bio- and geospheres to rapid millennial-scale climate changes observed in our cores results from the nature of hydrological changes affecting the seasonal rainfall pattern.

Both data and modeling studies have shown that phases of abrupt climate change coinciding with the Heinrich events known from the North Atlantic were phases of increased humidity and precipitation in tropical South America. A southward displacement of the ITCZ and enhanced northeast trade winds were suggested to be the source of moisture $(15,19,20)$. Drier El Niño-like conditions in the Cariaco Basin watershed have been inferred for the late Holocene. These were ascribed to a southward migration of the ITCZ in consequence of warmer surface water in the equatorial Pacific and Atlantic like that currently observed during El Niño events (21). Warming of the western tropical Atlantic is also indicated for the YD and H1 $(22,23)$. Therefore, it is most likely that the moisture brought to northeast Brazil during times of Heinrich events resulted from the southward displacement of the ITCZ and enhanced northeast trade winds (24).

These findings have important implications for the reconciliation of terrestrial and marine paleoclimate records and their use for the prediction of consequences of future climate change. In accordance with present-day observations of the ecological response to climate change (18), our findings underscore the importance of regional factors over approximated global averages in this respect for the recent past. Regional climate and hydrology have to be considered a major factor in determining the ecological response to rapid-scale climate change. This has to be taken into account when terrestrially derived proxies are used for the interpretation of paleoclimate records. 
References and Notes

1. M. Sarnthein et al., Eos 81, 625 (2000).

2. R. A. Kerr, Science 292, 660 (2001).

3. W. S. Broecker, S. Hemming, Science 294, 2308 (2001).

4. E. Bard, F. Rostek, C. Sonzogni, Nature 385, 707 (1997).

5. M. Stute et al., Science 269, 379 (1995).

6. I. Farrera et al., Clim. Dyn. 15, 823 (1999)

7. K. A. Hughen, T. I. Eglinton, L. Xu, M. Makou, Science 304, 1955 (2004); published online 20 May 2004 (10.1126/science.1092995).

8. R. S. Bradley, Paleoclimatology (Academic Press, San Diego, CA, ed. 2, 1991)

9. H. W. Arz, J. Pätzold, G. Wefer, Quat. Res. 50, 157 (1998).

10. H. Behling, H. W. Arz, J. Pätzold, G. Wefer, Quat. Sci. Rev. 19, 981 (1999).

11. High $\mathrm{x}$-ray fluorescence intensities of $\mathrm{Ca}$ are related to low $\mathrm{Fe}$ and $\mathrm{Ti}$ intensities and correlate well with the geochemical $\mathrm{CaCO}_{3}$ content (9). $\mathrm{Fe}$ and $\mathrm{Ti}$ are related to siliciclastic components and have been shown to vary directly with the terrigenous mineral fraction of sediments (25). In a similar way, an increased supply of river-borne materials caused by millennial-scale hydrological changes has been inferred from increased $\mathrm{Fe}$ and $\mathrm{Ti}$ abundances in sediment cores from the Cariaco Basin (26)

12. G. Fischer, Mar. Chem. 35, 581 (1991).

13. E. M. Galimov, The Biological Fractionation of Isotopes (Academic Press, San Diego, CA, 1985).

14. Sedimentary $\delta^{15} \mathrm{~N}$ can be altered by several processes, like degree of nutrient use in the water column, nitrification or denitrification, organic matter diagenesis, and material inputs from different sources $(27,28)$. In our case, low primary productivity of the oligotrophic and well-aerated waters (29) suggests that $\delta^{15} \mathrm{~N}$ alteration due to denitrification or surface nutrient use is negligible. The notion that $\delta^{15} \mathrm{~N}$ reflects the degree of OM degradation in our cores is also supported by amino acid data. High proportions of the nonprotein amino acids $\beta$-alanine and $\gamma$-aminobutyric acid in the beginning of a Heinrich event, indicating a high degree of OM degradation (30), decrease gradually toward its end (31).

15. M.-P. Ledru, P. Mourguiart, G. Ceccantini, B. Turcq, A. Sifeddine, Geology 30, 275 (2002).

16. Because the shelf break is located at about $50-\mathrm{m}$ water depth in the investigated area, sea level was below it at least during the most pronounced events correlated with $\mathrm{H} 1$ and $\mathrm{H} 6$ but probably throughout the entire period of marine isotope stages 2 to 4 $(32,33)$. Therefore, shelf erosion due to sea level change should have been unimportant throughout this period.

17. T. J. Crowley, Paleoceanography 14, 271 (1999).

18. G.-R. Walther et al., Nature 416, 389 (2002).

19. P. A. Baker et al., Nature 409, 698 (2001).

20. A. J. Broccoli, J. Clim. 13, 951 (2000).

21. G. H. Haug, K. A. Hughen, D. M. Sigman, L. C. Peterson, U. Röhl, Science 293, 1304 (2001).

22. C. Rühlemann, S. Mulitza, P. J. Müller, G. Wefer, R. Zahn, Nature 402, 511 (1999).

23. H. W. Arz, J. Pätzold, G. Wefer, Earth Planet. Sci. Lett. 167, 105 (1999).

24. Alternatively, the moisture could originate from the south. If global wind systems became more zonal during cold phases as has been suggested (34), the boreal winter ITCZ should have shifted northward. In our case, this would imply a southern moisture source responsible for the increased precipitation during Heinrich events, which could have been provided from southeast trade winds and/or polar advections. Currently the high rainfall south of Recife is restricted to the coastal stretch. The orographic barrier of the Brazilian highlands prevents substantial transport of moisture to the north and to the west. Therefore and for reasons given in the text, a southern source of moisture is rather unlikely. The suggested southward migration of the ITCZ would also help to explain the time lag of about 1000 years between the pollen records of Lagoa do Caço and that of our marine core, despite the possible chron- ological uncertainties of site-to-site correlations. The southward displacement of the ITCZ has led to the observed patterns of sedimentation and vegetation development as described. The subsequent migration of the ITCZ to the northwest may then have led to a similar vegetation development about 1000 years later in the Lagoa do Caço region.

25. J. H. F. Jansen, S. J. Van der Gaast, B. Koster, A. Vaars, Mar. Geol. 151, 143 (1998).

26. L. C. Peterson, G. H. Haug, K. A. Hughen, U. Röhl, Science 290, 1947 (2000).

27. E. Wada, A. Hattori, Nitrogen in the Sea: Forms, Abundances, and Rate Processes (CRC Press, Boca Raton, FL, 1991).

28. M. A. Altabet, R. Francois, Global Biogeochem. Cycles 8, 103 (1994).

29. H. T. Barretto, C. P. Summerhayes, J. Sediment. Petrol. 45, 822 (1975).

30. T. C. Jennerjahn, V. Ittekkot, Mar. Geol. 161, 129 (1999).
31. T. C. Jennerjahn et al., unpublished data.

32. J. Chappell, N. J. Shackleton, Nature 324, 137 (1986).

33. R. G. Fairbanks, Nature 342, 637 (1989).

34. S. W. Hostetler, A. C. Mix, Nature 399, 673 (1999).

35. L. Vidal et al., Earth Planet. Sci. Lett. 146, 13 (1997)

36. J. F. McManus et al., Nature 371, 326 (1994).

37. We thank M.-P. Ledru for providing pollen data from Lagoa do Caçó, A. Suthhof for helpful comments, and A. Cremer and D. Dasbach for laboratory work. The manuscript benefited from the constructive criticism of two anonymous reviewers. This work was supported by the German Federal Ministry for Education and Research and by the DFG to H.B. Data are available at www.pangaea.de.

7 July 2004; accepted 15 November 2004

Published online 2 December 2004;

10.1126/science. 1102490

Include this information when citing this paper.

\title{
Seismological Constraints on Core Composition from Fe-O-S Liquid Immiscibility
}

\author{
George Helffrich $^{1 *}$ and Satoshi Kaneshima ${ }^{2}$
}

\begin{abstract}
Earth's core is composed primarily of iron (Fe) with about $10 \%$ by weight of lighter elements. The lighter elements are progressively enriched in the liquid outer core as the core cools and the inner core crystallizes. Thermodynamic modeling of Fe-O-S liquids shows that immiscible liquids can exist at outer-core pressures (136 to 330 gigapascals) at temperatures below 5200 kelvin and lead to layering in the outer core if the concentrations of the lighter elements are high enough. We found no evidence for layering in the outer core in the travel times and wave forms of P4KP seismic waves that reflect internally in the core. The absence of layers therefore constrains outer-core compositions in the Fe-O-S system to be no richer than $6 \pm 1$ weight \% (wt \%) O and 2 to 15 wt \% S. A single core liquid composition of $10.5 \pm 3.5 \mathrm{wt} \% \mathrm{~S}$ and $1.5 \pm 1.5 \mathrm{wt} \% \mathrm{O}$ is compatible with wave speeds and densities throughout the outer core.
\end{abstract}

The outer core is composed of liquid iron mixed with about $10 \mathrm{wt} \%$ lighter elements (1-3). Although these elements are a minor constituent by weight, they may affect the dynamic behavior of the core. The light elements may control the rate of cooling, the type of crystallization, and the final composition of the solid inner core $(4,5)$. Partitioning of the light elements between the inner core and the liquid outer core affects the gravitational potential energy available to power the geodynamo as well $(6,7)$.

Liquid immiscibility occurs widely in ironrich liquid systems and is the physical basis for the smelting process. In iron-bearing systems such as Fe-O-S, Fe-C-S, and Fe-Si-S, one of the two coexisting liquids is rich in $\mathrm{Fe}$, whereas the other is richer in $\mathrm{S}$ or $\mathrm{O}(4,8,9)$. The liquid densities differ appreciably, leading to buoyant separation and stratification in the system.

${ }^{1}$ Earth Sciences, University of Bristol, Wills Memorial Building, Queen's Road, Bristol BS8 1RJ, UK. ${ }^{2}$ Earth and Planetary Science, Tokyo Institute of Technology, 12-1 Ookayama, Meguro-ku, Tokyo 152-6551, Japan.

*To whom correspondence should be addressed. E-mail: george@geology.bristol.ac.uk
As the core cools and the inner core crystallizes, enriching the outer core in the light element because it preferentially partitions into the liquid phase, immiscibility might also develop. The differences in the properties of the liquid could lead to layering in the core, and seismic analysis may be able to detect this layering. There is already suggestive seismic evidence of layering (10-12). To establish whether layering is possible, we need to determine whether immiscibility exists under core conditions, how thick the liquid layer might be, and what the densities and wave speeds in these liquids are.

To estimate layer thickness, we assume a mass-balance model of inner-core crystallization similar to that described in (6). The density jump $\Delta \rho_{\text {ICB }}$ at the inner core-outer core boundary is between 0.5 and $1.6 \mathrm{Mg} \mathrm{m}^{-3}$, with values of $<1.0 \mathrm{Mg} \mathrm{m}^{-3}$ most probable (13-15). This density increase reflects two processes: contraction from the liquid to the solid form and exclusion of the light element from the inner core's crystalline structure. Quantum-mechanical calculations of the properties of $\mathrm{Fe}$ at core conditions indicate that $0.21 \mathrm{Mg} \mathrm{m}^{-3}$ of $\Delta \rho_{\text {ICB }}$ is due to solid con- 